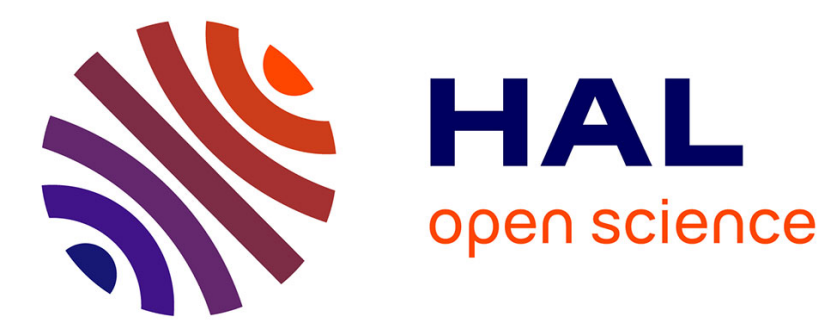

\title{
Coal pyrolysis in a rotary kiln: Part I. Model of the pyrolysis of a single grain
}

Fabrice Patisson, Etienne Lebas, François Hanrot, Denis Ablitzer, Jean-Leon Houzelot

\section{- To cite this version:}

Fabrice Patisson, Etienne Lebas, François Hanrot, Denis Ablitzer, Jean-Leon Houzelot. Coal pyrolysis in a rotary kiln: Part I. Model of the pyrolysis of a single grain. Metallurgical and Materials Transactions B, 2000, 31 (2), pp.381-390. 10.1007/s11663-000-0056-5 . hal-01411200

\author{
HAL Id: hal-01411200 \\ https://hal.science/hal-01411200
}

Submitted on 7 Dec 2016

HAL is a multi-disciplinary open access archive for the deposit and dissemination of scientific research documents, whether they are published or not. The documents may come from teaching and research institutions in France or abroad, or from public or private research centers.
L'archive ouverte pluridisciplinaire HAL, est destinée au dépôt et à la diffusion de documents scientifiques de niveau recherche, publiés ou non, émanant des établissements d'enseignement et de recherche français ou étrangers, des laboratoires publics ou privés. 

april 2000, pp. 381-390. doi:10.1007/s11663-000-0056-5.

This paper (and Part II) received TMS Champion H. Mathewson Award 2003 as the best paper of the year 2000 published in MMTB

\title{
Coal Pyrolysis in a Rotary Kiln. Part 1: Model of the Pyrolysis of a Single Grain
}

\author{
Fabrice Patisson, Etienne Lebas, François Hanrot, \\ Denis ABLitZER AND JEAN-LEON HouZELOT
}

\begin{abstract}
A mathematical model is presented describing the pyrolysis of a single grain of coal and designed to be incorporated in an overall model simulating the rotary kiln coal pyrolysis process. The grain model takes into account the principal physical phenomena occurring during the conversion of coal to coke, namely heat transfer towards and within the grain, drying of the coal, and the evolution of volatile species. Particular care has been taken in the determination of the thermophysical and kinetic parameters necessary for the model. Thus, the drying kinetics for Lorraine coal were measured by thermogravimetry. The kinetics of pyrolysis were determined by both thermogravimetry and gas phase chromatography in order to separately monitor the evolution of the 9 gaseous species considered. The true specific heat and the thermal conductivity of the solid were also mesured as a function of temperature. The numerical model, based on the finite volume method, calculates the temperature, the composition and the mass flowrates for the different gases evolved at each point in the grain at any instant of time. The model was finally validated by comparing the calculated and measured values of the overall conversion of the pyrolysis reaction and the temperature at the center of the grain.
\end{abstract}




\section{INTRODUCTION}

The rotary kiln coal pyrolysis process is used to produce coke for electrometallurgical applications, for which users require high reactivity and porosity. Compared to a conventional coke oven, the rotary kiln process has two distinctive features; it uses coal grains 1 to $2 \mathrm{~cm}$ in diameter, which are converted to coke grains of essentially identical size, and coking is completed in about $1 \mathrm{~h}$, instead of 15 to $20 \mathrm{~h}$. The relatively rapid heating rate promotes the formation of highly porous coke grains.

The present two articles describe a complete mathematical model of the kiln designed to assist process optimization. A model of this sort requires the description of the various transformations occurring in the solid grains during pyrolysis caused by heating. This first paper presents a thermal and kinetic model of the pyrolysis of a single coal grain, which will be called the grain model. The overall model of the rotary kiln will be described in the second article.

As it passes through the rotary kiln, due to the increase in temperature, each coal grain successively undergoes drying, then devolatilization (i.e. evolution of volatile species). The aim of the grain model is to describe these transformations quantitatively. The model calculates the advance of the different devolatilization reactions, together with the instantaneous temperature profile within the grain and the principal evolved gas fluxes, as a function of time, for known but variable external conditions (composition of the surrounding gaseous atmosphere, gas temperature, temperature of the facing solid surfaces). The grain model is of the physical-chemical type, i.e. it is based on a description of the real physical, chemical and thermal processes occurring within and immediately around the grain. 
Most of the kinetic data employed were obtained from specific experiments. This data obviously depends strongly on the nature of the coal considered and on the variation of the external conditions. The present study was limited to a French coal from Lorraine, a non caking, non swelling variety with a high concentration of volatile matter. The principal characteristics of this coal are given in Table 1. As regards the external conditions, only variations close to those encountered in an industrial rotary kiln were considered, namely atmospheric pressure, a gas mixture composed of air and volatile species, and a heating rate between 8 and $30 \mathrm{~K} \mathrm{~min}^{-1}$.

Table I. Characteristics of Lorraine Coal

\begin{tabular}{lc}
\hline \multicolumn{1}{c}{ Characteristic } & Wt Pct of Dry Coal \\
\hline Volatile matter & 36.1 \\
Ash content & 5.5 \\
Elementary composition & \\
\hline $\mathrm{C}$ & 80.4 \\
$\mathrm{H}$ & 5.2 \\
$\mathrm{~S}$ & 0.9 \\
$\mathrm{~N}$ & 1.1 \\
$\mathrm{Cl}$ & 0.4 \\
O (by difference) & 7.3 \\
Swelling index & 1 \\
Grain diameter & 4 to $20 \mathrm{~mm}$ \\
\hline
\end{tabular}

The present paper first of all discusses the determination of the kinetic and thermophysical parameters necessary for the model, then goes on to describe the mathematical model itself, followed by the results obtained and validation by comparison with measurements.

\section{DRYING}

The coal charged into the rotary kiln contains moisture, so that pyrolysis is preceded by drying. The absolute initial moisture content, given by the ratio between 
the weight of free water and the weight of dry coal, $w_{f w_{0}}$, is typically from 2 to $5 \%$. In order to describe the loss of water in the grain and rotary kiln models, it is necessary to know the instantaneous drying rate of the coal grains.

Since very little has been published in the literature concerning the drying of coal, we have specifically performed a thermogravimetric study of the drying of Lorraine coal grains. The aim was to determine a simple kinetic law for drying as a function of temperature and moisture content. No attempt was made to describe water transfer processes within the grains in microscopic detail. The study has been described elsewhere by Hanrot, ${ }^{[1]}$ who concludes that the drying rate can be represented by a first order law :

$$
v_{d r}=k_{d r} \rho_{d c} w_{f w}
$$

where $\rho_{d c}$ is the dry coal apparent density and where the rate constant $k_{d r}$ is an Arrhenius function of temperature:

$$
k_{d r}=k_{0 d r} \exp \left(-\frac{E_{d r}}{\mathrm{R} T}\right)
$$

with $k_{0 d r}=3.11 \mathrm{~s}^{-1}$ and $E_{d r}=27700 \mathrm{~J} \mathrm{~mol}^{-1}$, for the Lorraine coal grains, as determined from the drying experiments.

Figure 1 shows the good agreement between the variation of the drying rate calculated from Eq. [1] and that determined by thermogravimetric measurements as a function of time during heating in nitrogen at $8.7 \mathrm{~K} \mathrm{~min}^{-1}$, from 20 to $320{ }^{\circ} \mathrm{C}$. The drying rate increases with rise in temperature and decreases as the residual moisture content diminishes, explaining the existence of a maximum in the curve. 


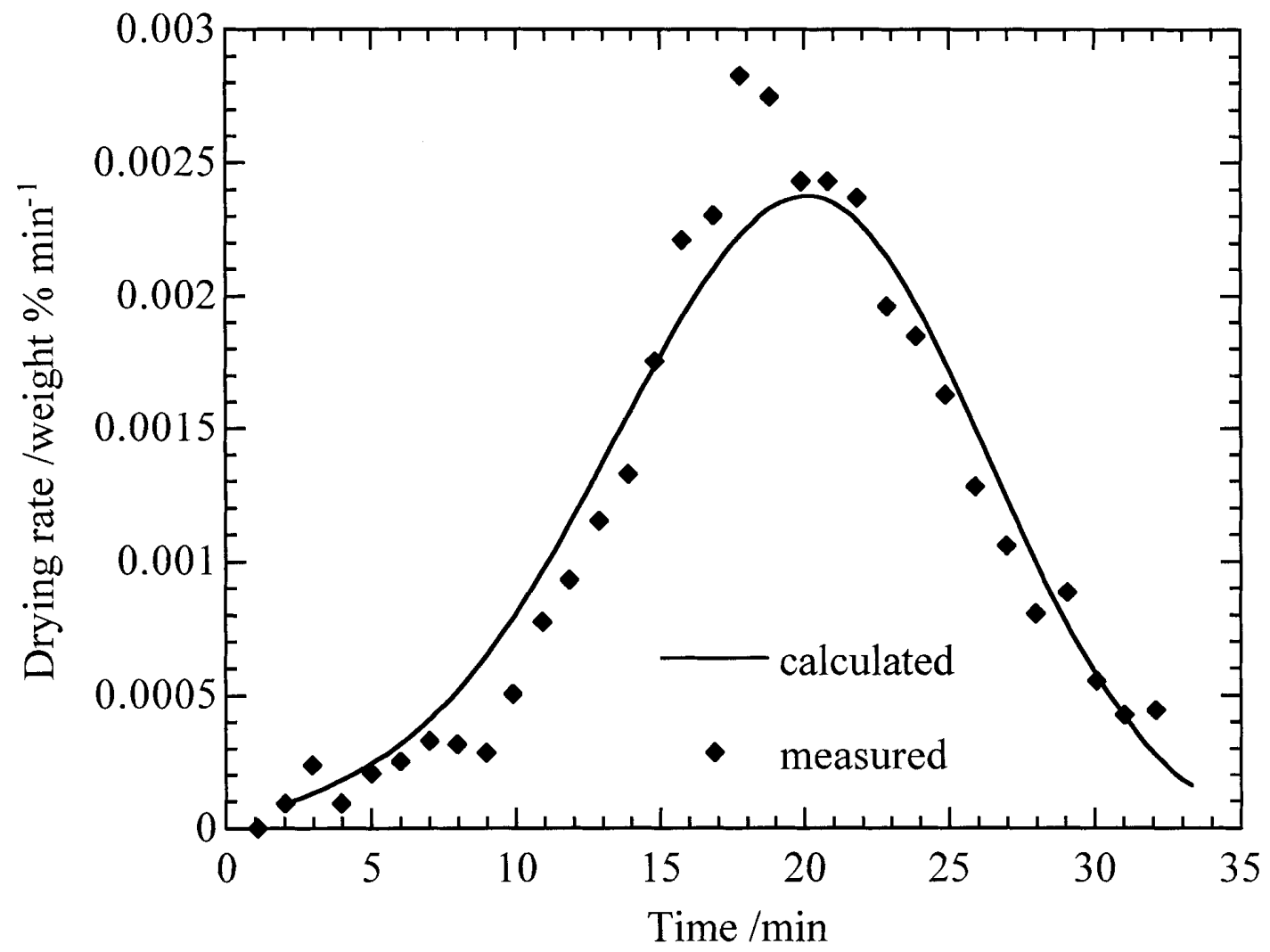

Fig. 1-Comparison of measured and calculated drying rates for a coal grain heated at $8.7 \mathrm{~K} \mathrm{~min}^{-1}$ under nitrogen from $20{ }^{\circ} \mathrm{C}$ to $320{ }^{\circ} \mathrm{C}$.

\section{PYROLYSIS}

\section{A. Description}

The pyrolysis of coal leads to the formation of three classes of product: coke, tars and gases. Coke is the solid residue of the transformation process, and is richer in carbon than the coal. The solid in the course of conversion will be called semi-coke. The tars and gases are the volatile matter and represent 4 to $45 \%$ of the weight of the coal, depending on its type. Coal is a complex natural organic substance. When heated, the weakest chemical bonds begin to break at $300-400^{\circ} \mathrm{C}$, producing molecular fragments, in a process termed depolymerization. These fragments can lead to the 
formation of tars if they are small enough to be vaporized and transported outside of the coal grain. Simultaneously, the decomposition of the functional groups gives rise to the evolution of light gases, principally $\mathrm{CO}_{2}, \mathrm{H}_{2} \mathrm{O}, \mathrm{CH}_{4}$ and aliphatic $\mathrm{C}_{2}$ compounds. Cracking, which occurs beyond $550-600{ }^{\circ} \mathrm{C}$, causes the liberation of $\mathrm{CO}$ and $\mathrm{H}_{2}$. For the purpose of the present study, the following 9 principal volatile species were considered: constitutive water $(\mathrm{cw})$, tars, ethylene $\left(\mathrm{C}_{2} \mathrm{H}_{4}\right)$, ethane $\left(\mathrm{C}_{2} \mathrm{H}_{6}\right)$, acetylene $\left(\mathrm{C}_{2} \mathrm{H}_{2}\right)$, carbon dioxide $\left(\mathrm{CO}_{2}\right)$, methane $\left(\mathrm{CH}_{4}\right)$, carbon monoxide $(\mathrm{CO})$ and hydrogen $\left(\mathrm{H}_{2}\right)$.

The literature review reported by Solomon et al. ${ }^{[2]}$ reveals a wide diversity of results obtained in studies of coal pyrolysis kinetics. These discrepancies are explained partially by differences in the types of coal employed, together with the intrinsically heterogeneous composition of each material, which naturally creates scatter in the measurements, and partially by variations in experimental conditions from one study to another (heating rates, temperature measurement techniques, etc.). We therefore decided to undertake a study of the pyrolysis kinetics of Lorraine coal, in conditions close to those encountered in an industrial rotary kiln.

The mechanisms liable to influence the pyrolysis process in a coal grain are: (i) heat transfer from the outside towards the surface of the grain, (ii) conduction of heat within the grain, (iii) the kinetics and (iv) the heat effect of the devolatilization reactions, (v) transport of the volatile matter from the inside to the outside of the grain, (vi) heat exchanges between the volatile matter and the solid during this internal transport, (vii) secondary cracking reactions of the volatile species during their internal transport, (viii) swelling and cracking of the grain, (ix) increase in the pressure within the grain due to the formation of gases. 
The increase in internal pressure during pyrolysis (ix) has been extensively treated in the literature. ${ }^{[3-5]}$ Only pressures greater than 2 bars appear to have a significant influence on the rate of devolatilization. According to published calculated internal pressures values, this possibility concerns only rapid pyrolysis $\left(>30 \mathrm{~K} \mathrm{~s}^{-1}\right)$.

The influence of internal transport of volatiles (v) is also related to the heating rate. For high rates, Howard and Essenhigh ${ }^{[6]}$ consider that this phenomenon controls volatile matter removal. But Solomon et al..$^{[2]}$ believe that, in the majority of cases, the only effect related to transport of volatiles is a modification of the tar and gas yield. Tars with limited diffusion rates tend to crack (vii) to lighter products which can diffuse more readily.

It can be concluded that, in the conditions of interest here (non-swelling coal, with grains from 4 to $20 \mathrm{~mm}$ in size, pyrolysed at a rate between 8 and $30 \mathrm{~K} \mathrm{~min}^{-1}$ ), the description of the heat transfer mechanisms (i, ii, iv, vi) and the kinetics of devolatilization (iii) are sufficient to correctly represent the pyrolysis process. Only these mechanisms are therefore considered in the grain model.

\section{B. Experimental study}

In order to determine the exact order in which the different volatile species are eliminated, together with the associated kinetics, the pyrolysis of coal was studied experimentally in a Setaram B70 thermobalance.

For each experiment, a single grain, weighing about $0.6 \mathrm{~g}$, with a diameter of about $10 \mathrm{~mm}$, was suspended from the balance beam using a platinum wire. The grain was heated from 20 to $850^{\circ} \mathrm{C}$ in $95 \mathrm{~min}$ (i.e. $8.7 \mathrm{~K} \mathrm{~min}^{-1}$ ), then held at $850^{\circ} \mathrm{C}$ until pyrolysis was complete. This heating program corresponds to that of the charge in the rotary kiln at Carling (France). The normal volume flowrate of nitrogen or helium 
carrier gas was $50 \mathrm{~cm}^{3} \mathrm{~min}^{-1}$, controlled by a mass flowmeter. To prevent any oxidation of the coke formed during the experiment, all traces of oxygen were eliminated by the prior establishment of a vacuum in the furnace, followed by a gas purge. In addition to the continuously measured weight loss, the exit gases were analyzed by chromatography. At regular intervals, as short as possible, a known quantity of exit gas was injected into the Carlo Erba 4300 chromatograph. The carrier gases, columns and detectors employed are given in Table 2 as a function of the gas to be analyzed.

Table II. Gas Analysis Devices

\begin{tabular}{ccccc}
\hline $\begin{array}{c}\text { Gas } \\
\text { Analyzed }\end{array}$ & Gas & Gas & Chromatograph & Detector \\
\hline $\mathrm{He}$ & $\mathrm{He}$ & active charcoal & $\mathrm{N}_{2}$ & catharimeter \\
$\mathrm{H}_{2}$ & $\mathrm{~N}_{2}$ & active charcoal & $\mathrm{N}_{2}$ & catharimeter \\
$\mathrm{CO}, \mathrm{N}_{2}$ & $\mathrm{~N}_{2}$ & molecular sieve & $\mathrm{He}$ & catharimeter \\
$\mathrm{CO}_{2}$ & $\mathrm{He}$ or $\mathrm{N}_{2}$ & carbosieve & $\mathrm{He}$ & catharimeter \\
Hydrocarbons & $\mathrm{He}$ or $\mathrm{N}_{2}$ & porapak-N & $\mathrm{N}_{2}$ & FID \\
\hline
\end{tabular}

The analysis of the exit gases gives the composition in $\mathrm{C}_{2} \mathrm{H}_{4}, \mathrm{C}_{2} \mathrm{H}_{6}, \mathrm{C}_{2} \mathrm{H}_{2}, \mathrm{CO}_{2}$, $\mathrm{CH}_{4}, \mathrm{CO}$ and $\mathrm{H}_{2}$. The reproducibility of the measurements is good. However, it is better for the hydrocarbons, analyzed using a flame ionization detector, than for the other gases, analyzed by catharimetry. Knowing the flowrate of carrier gas injected into the thermobalance, it is possible to calculate the instantaneous mass flowrates of the different gases evolved. The mass flowrate of tars (in fact tars + water + benzols), which are not analyzed, is obtained from the difference between the rate of overall weight loss and the sum of the mass flowrates of the analyzed gases.

Finally, calculation of the areas beneath the curves of the mass flowrates of volatiles versus time enabled the establishment of Table 3, which gives the composition of the volatile species produced by pyrolysis of Lorraine coal at $8.7 \mathrm{~K} \mathrm{~min}^{-1}$. The concentrations of constitutive water, benzols, $\mathrm{NH}_{3}$ and $\mathrm{H}_{2} \mathrm{~S}$, which could not be measured at the thermobalance outlet, were determined by a separate analysis in a Jenker crucible. Compared to a coke oven gas, the volatile species produced here differ 
by a high $\mathrm{H}_{2}$ content and a low $\mathrm{CH}_{4}$ content, due to more extensive cracking of methane, associated with the more rapid heating rate.

Table III. Composition of Volatile Species Produced by Lorraine Coal Pyrolyzed at $8.7 \mathrm{~K} \mathrm{~min}^{-1}$

\begin{tabular}{ccccccc}
\hline & \multicolumn{5}{c}{ In Wt Pct of Dry Coal } \\
\cline { 2 - 7 } Tars & $\begin{array}{c}\text { Constitutive } \\
\text { Water }\end{array}$ & $\begin{array}{c}\text { Analyzed } \\
\text { Gases }\end{array}$ & $\begin{array}{c}\text { Others (Benzols, } \\
\left.\mathrm{NH}_{3}, \mathrm{H}_{2} \mathrm{~S}\right)\end{array}$ \\
\hline 19.2 & 5.9 & \multicolumn{7}{c}{7.3} \\
& \multicolumn{5}{c}{ In Mol PcT } \\
\hline $\mathrm{H}_{2}$ & $\mathrm{CH}_{4}$ & $\mathrm{CO}$ & $\mathrm{CO}_{2}$ & $\mathrm{C}_{2} \mathrm{H}_{6}$ & $\mathrm{C}_{2} \mathrm{H}_{4}$ & $\mathrm{C}_{2} \mathrm{H}_{2}$ \\
\hline 70.2 & 12.8 & 6.5 & 1.8 & 1.7 & 0.4 & 0.7 \\
\hline
\end{tabular}

\section{Kinetic laws}

Numerous authors (e.g. Anthony and Howard ${ }^{[7]}$ ) represent the kinetics of pyrolysis by a set of first order reactions, with identical frequency factors and activation energies varying according to a gaussian distribution. This solution takes into account the large number of chemical reactions involved in the pyrolysis process, but does not really distinguish between the devolatilizations of the different volatile constituents of the coal. In a rotary kiln, pyrolysis is sufficiently slow for the evolution of tars, methane and hydrogen, for example, to be distinctly separated. These successive evolutions occur in different zones of the furnace, and influence the combustion phenomena and hence the temperature profiles in both the solid charge and the gas phase. We therefore preferred an approach in which each volatile constituent has its own individual evolution kinetics. Each species can then be considered to be evolved either via a single first order reaction ${ }^{[8]}$ or according to a set of first order reactions with different activation energies. ${ }^{[9]}$ Solomon et al. ${ }^{[2]}$ recommend the second method, which gives kinetic parameters valid over a wide range of heating rates. However, in order not to unduly complicate our model, we chose to represent the evolution of each constituent 
by a single first order reaction, while verifying that the kinetics obtained were valid for the different heating rates used in practice.

The devolatilization rate $v_{j}$ of each volatile species is thus represented by an equation

$$
v_{j}=k_{d e v, j} \rho_{d c} w_{j}
$$

where $j$ designates the volatile species concerned $\left(j=c w\right.$, tar, $\mathrm{C}_{2} \mathrm{H}_{4}, \mathrm{C}_{2} \mathrm{H}_{6}, \mathrm{C}_{2} \mathrm{H}_{2}, \mathrm{CO}_{2}$, $\mathrm{CH}_{4}, \mathrm{CO}$ or $\left.\mathrm{H}_{2}\right), w_{j}$ is the weight fraction of $j$ per unit weight of dry coal and $k_{d e v, j}$ is the rate constant for devolatilization of the species $j$, which varies with temperature via an Arrhenius law

$$
k_{d e v, j}=k_{0 d e v, j} \exp \left(-\frac{E_{d e v, j}}{\mathrm{R} T}\right)
$$

A rate law such as that described by equation [3] assumes that the kinetics are not controlled by diffusional processes, in accordance with the comments made in $\S$ III.A.

The experimental mass flowrate curves for the gases as a function of time can be used to calculate the kinetic constants $k_{0 d e v, j}$ and $E_{d e v, j}$ for each species $j$, by minimizing the sum of the squares of the deviations between the points on the theoretical curve and those on the experimental curve. Table 4 gives the values obtained. The constants for the constitutive water, whose evolution could not be followed with the apparatus employed, are taken from the literature. ${ }^{[2]}$

Table IV. Kinetic Parameters of the Devolatilization Reactions

\begin{tabular}{ccc}
\hline Species & $k_{0 \text { dev }}, \mathrm{s}^{-1}$ & $E_{\text {dev }}, \mathrm{kJ} \mathrm{mol}^{-1}$ \\
\hline Tars & $8.85 \times 10^{5}$ & 123.8 \\
$\mathrm{H}_{2} \mathrm{O}$ & 1.1 & 50.3 \\
$\mathrm{CH}_{4}$ & 27.9 & 72.4 \\
$\mathrm{CO}$ & 32.6 & 78.7 \\
$\mathrm{CO}_{2}$ & 1.12 & 49.4 \\
$\mathrm{H}_{2}$ & 316.4 & 108.5 \\
$\mathrm{C}_{2} \mathrm{H}_{6}$ & $7.19 \times 10^{4}$ & 110.6 \\
$\mathrm{C}_{2} \mathrm{H}_{4}$ & $1.02 \times 10^{6}$ & 126.5 \\
$\mathrm{C}_{2} \mathrm{H}_{2}$ & $4.21 \times 10^{19}$ & 350.9 \\
\hline
\end{tabular}


Figure 2 shows the calculated mass flowrate of the volatile species versus time during the pyrolysis of a coal grain at $8.7 \mathrm{~K} \mathrm{~min}^{-1}$. The order of evolution of the different species should be noted, particularly the late emission of hydrogen. For the sake of legibility, the measured points, which are very close to the calculated ones, were not plotted in this figure. A comparison with experiment is given below.

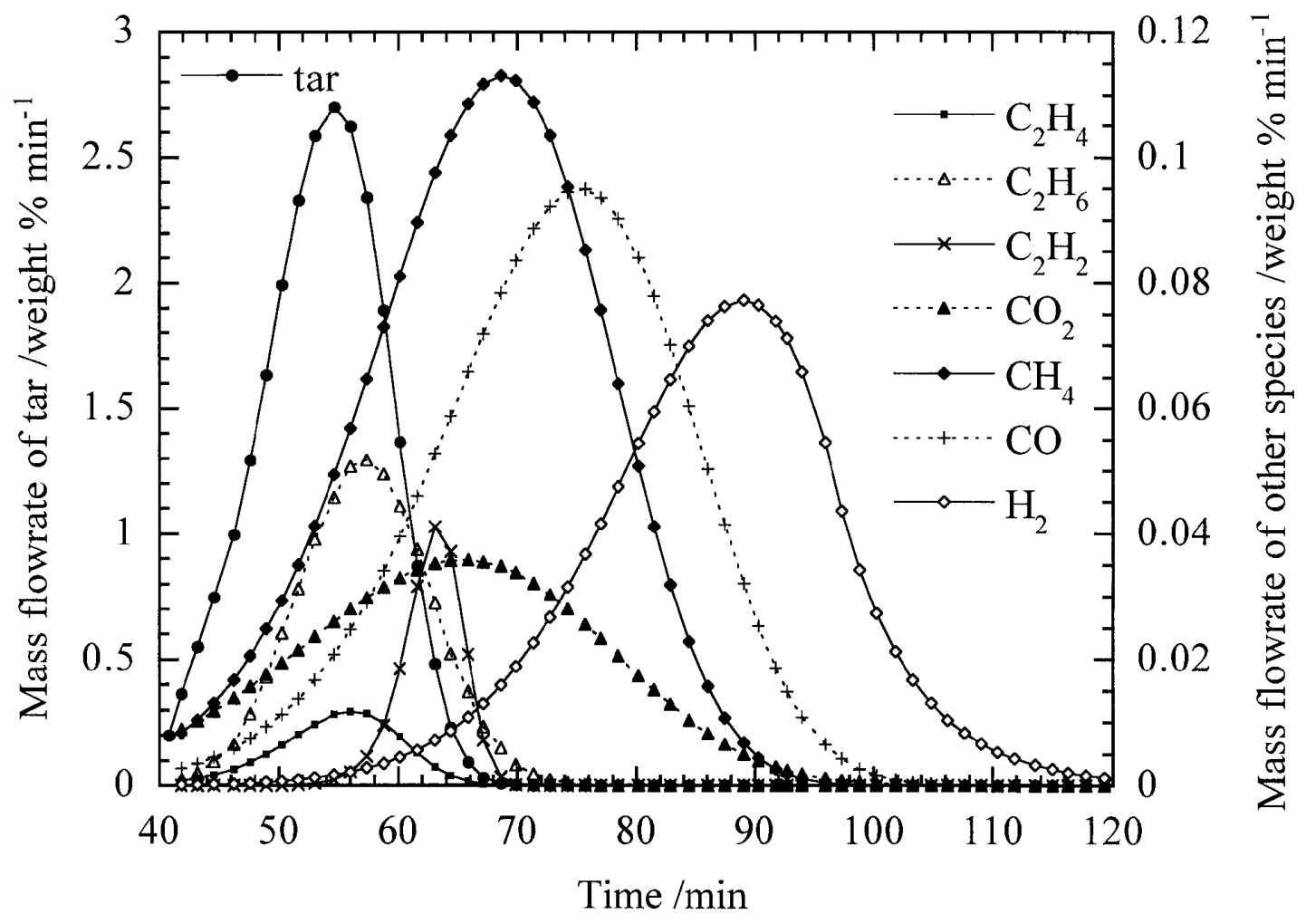

Fig. 2-Calculated mass flow rate of gases evolved during the pyrolysis of a coal grain at $8.7 \mathrm{~K} \mathrm{~min}^{-1}$.

\section{Influence of heating rate}

In order to study the influence of heating rate, the measurements described in §III.B were repeated for faster heating rates (i.e. 13.8 and $27.7 \mathrm{~K} \mathrm{~min}^{-1}$ ), corresponding to times of $60 \mathrm{~min}$ and $30 \mathrm{~min}$ between 20 and $850^{\circ} \mathrm{C}$. The latter value corresponds to the maximum coal heating rate in the pilot furnace at the Centre de Pyrolyse at 
Marienau (France). The results of these measurements are compared to the calculated values in Figure 3.

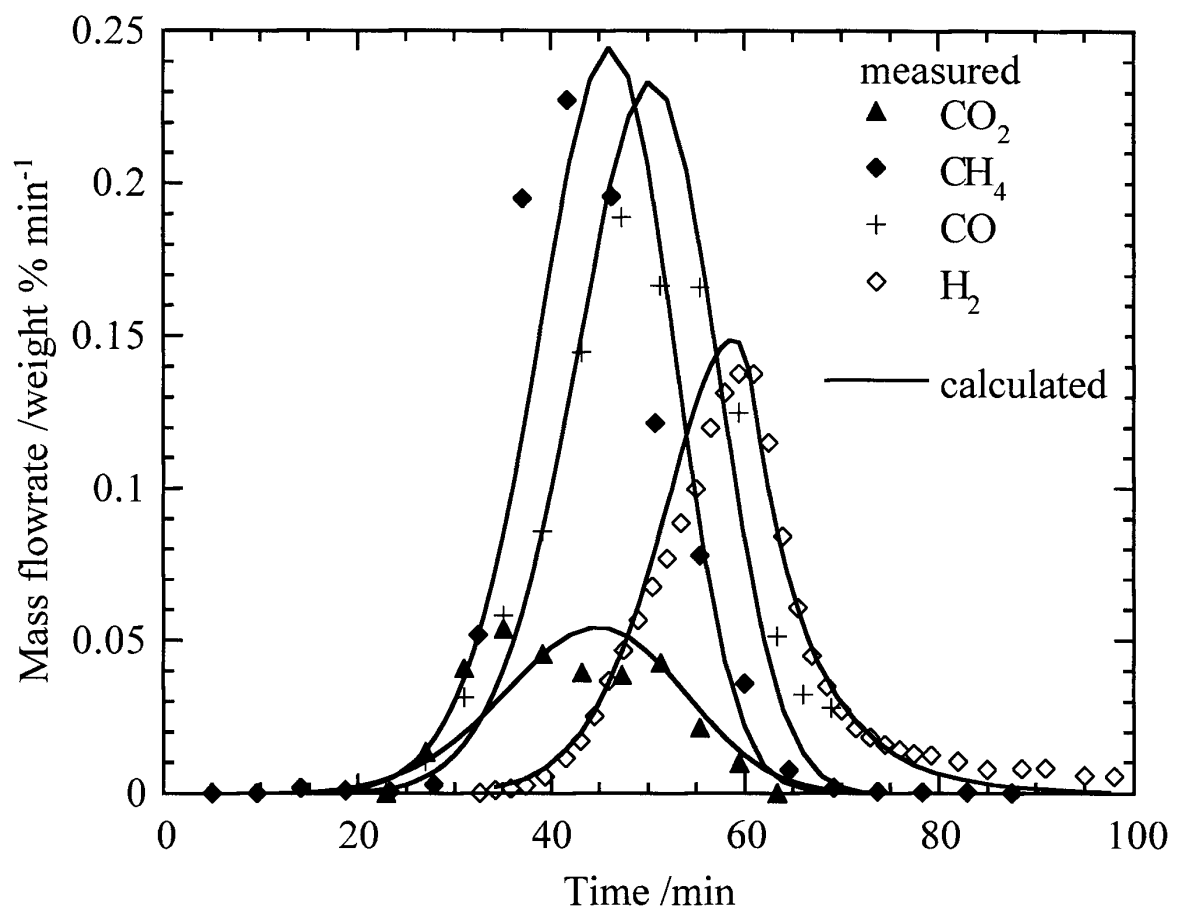

(a)

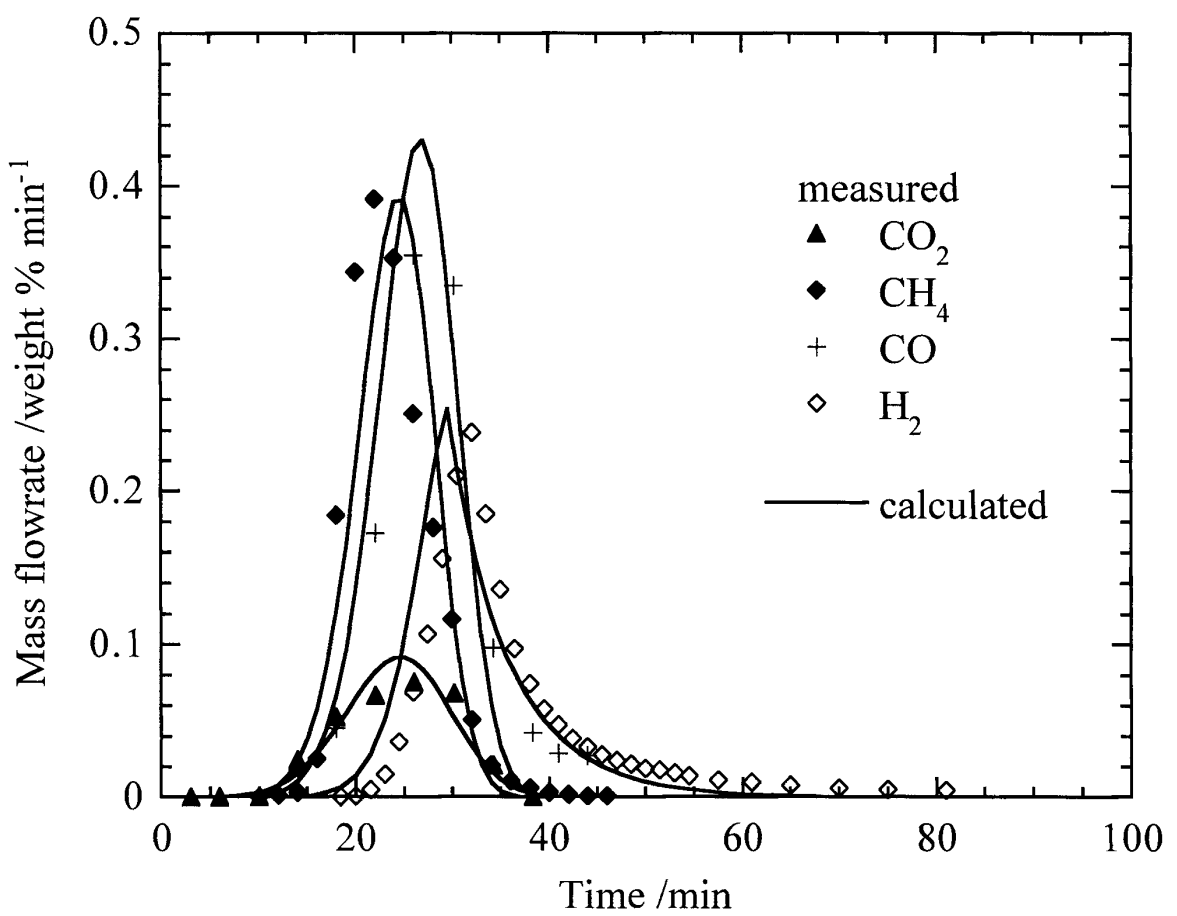

(b)

Fig. 3-Mass flow rates evolved during the pyrolysis of a coal grain at (a) 13.8 and (b) $27.7 \mathrm{~K} \mathrm{~min}^{-1}$. 
The calculations were performed using the constants obtained previously (cf. Table 4). It can be seen that, for these two new heating rates, the results of the calculated kinetics are very close to the measured values. This indicates that the kinetic model is well adapted for heating rates between 8.7 and $27.7 \mathrm{~K} \mathrm{~min}^{-1}$, and can therefore be applied to any pilot or industrial furnace operating in this range of heating rate.

However, an important consequence of the increase in heating rate concerns the nature of the volatile matter. Whereas the overall weight loss remains identical, Table 5 shows that the quantity of light gases increases, while that of tars diminishes. This observation is in agreement with the interpretation of Solomon et al..[2] mentioned in §III.A.

Table V. Quantity of Light Gases (in Weight Percent of Dry Coal) Produced by Pyrolysis of Lorraine Coal as a Function of Heating Rate

\begin{tabular}{ccccc}
\hline Rate, $\mathrm{K} \mathrm{min}^{-1}$ & $\mathrm{H}_{2}$ & $\mathrm{CH}_{4}$ & $\mathrm{CO}$ & $\mathrm{CO}_{2}$ \\
\hline 8.7 & 1.92 & 2.81 & 2.48 & 1.11 \\
13.8 & 2.50 & 3.88 & 4.26 & 1.24 \\
27.7 & 2.66 & 5.00 & 4.42 & 1.25 \\
\hline
\end{tabular}

\section{THERMOPHYSICAL PARAMETERS}

Pyrolysis is accompanied by a change in the structure of the coal, leading to a marked variation in its thermophysical properties. Modeling of heat transfer in the transient regime requires a knowledge of the density, the specific heat, the thermal conductivity and the emissivity of the solid (coal, semi-coke or coke) as a function of temperature, together with the enthalpy of the pyrolysis reactions. 


\section{A. Density}

The apparent density of a coal grain can be readily determined by measuring its mass and its volume. In the present case, the volume was measured using a water pycnometer after prior coating of the grain. The apparent density of a dry Lorraine coal grain was found to be $\rho_{d c}=1250 \mathrm{~kg} \mathrm{~m}^{-3}$. For wet coal, the value is given by

$$
\rho_{w c}=\rho_{d c}\left(1+w_{f w}\right)
$$

In the course of pyrolysis, the density of coal usually decreases due to swelling and the evolution of volatiles. Since the Lorraine coal has little tendency to swell, its volume was assumed to remain constant. The density is then derived from the variation in mass given by the kinetic laws.

\section{B. Specific heat}

The literature reviews of Merrick ${ }^{[10,11]}$ show that published specific heat values vary widely. Apart from the variety of coals, this is due to the difficulty in directly measuring the specific heat of semi-coke by calorimetry. Indeed, the pyrolysis reaction disturbs the measurement, due to both the heat of the reaction and the associated weight loss.

Hanrot et al. ${ }^{[12]}$ proposed an original method for overcoming this difficulty, and were able to experimentally determine the true specific heat of Lorraine coal, together with that of the semi-coke in the course of pyrolysis. The method consists in pyrolyzing coal samples at different temperatures between 300 and $1000^{\circ} \mathrm{C}$. The true specific heat of the semi-coke obtained is then measured by calorimetry between $20^{\circ} \mathrm{C}$ and the corresponding pyrolysis temperature for the specimen, the sample remaining inert over this range. The extreme points of the specific heat versus temperature curves then give 
the variation of the true specific heat of the coal during pyrolysis (cf. Figure 4). The specific heat can be seen to go through a maximum around $500^{\circ} \mathrm{C}$. The shape of this curve was predicted by Merrick's model ${ }^{[10]}$, but the values obtained were about $20 \%$ higher than those measured by Hanrot et al.[12]

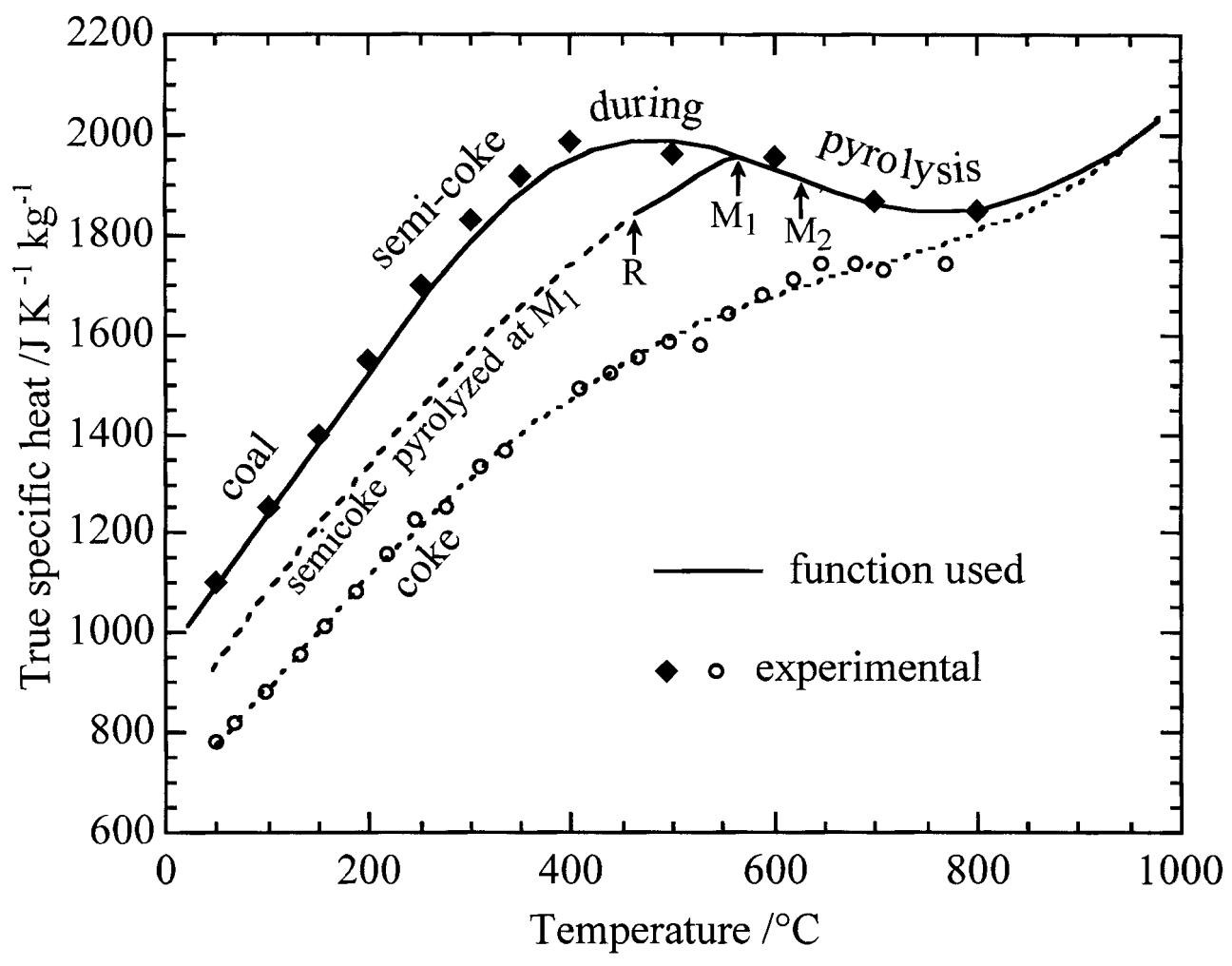

Fig. 4-True specific heat of Lorraine coal, semicoke during pyrolysis, and coke, as a function of temperature.

Figure 4 shows that the specific heat of coal during pyrolysis is not a simple function of temperature. A hysteresis phenomenon is observed due to the chemical transformations induced by the pyrolysis: Cooled coke does not have the same $c_{p}$ value as the coal at a given temperature. This must be allowed for in the thermal modeling of the rotary kiln, where the grains are heated or cooled, due to their movements within the charge. Thus, when a semi-coke grain previously heated to a temperature $\mathrm{M}_{1}$ subsequently cools to a temperature $R$, its specific heat follows the curve $M_{1} R$. When it 
is then reheated to $M_{2}$, it follows the curve $R M_{1}$, then $M_{1} M_{2}$. It is this method of calculation $^{[1]}$ that is used in the present model.

Finally, for wet coal, the influence of moisture is considered to be additive, so that

$$
c_{p_{w c}}=\frac{c_{p_{d c}}+w_{f w} c_{p_{f w}}}{1+w_{f w}}
$$

\section{Thermal conductivity}

Few studies of the thermal conductivity of coal are reported in the literature, apart from that of Badzioch et al., ${ }^{[13]}$ who made measurements on a large number of different coals and found no correlation between the amount of volatile matter and the value of the thermal conductivity. The curve in Figure 5 shows the variation of thermal conductivity with temperature.

The applicability of this curve to Lorraine coal was verified by measuring the thermal conductivity of the latter at different temperatures using the laser flash method. ${ }^{[14]}$ This technique consists in monitoring the thermal response transient on the rear face of a specimen whose front face is subjected to a laser flash. The parameter measured is the thermal diffusivity $a$ from which the conductivity $\lambda$ is derived via

$$
\lambda=a \rho c_{p}
$$

knowing $\rho(T)$ and $c_{p}(T)$. The results of these measurements are represented by the points in Figure 5. For the points at 600,700 and $800^{\circ} \mathrm{C}$, the specimens had previously undergone pyrolysis, as explained in §IV.B. 


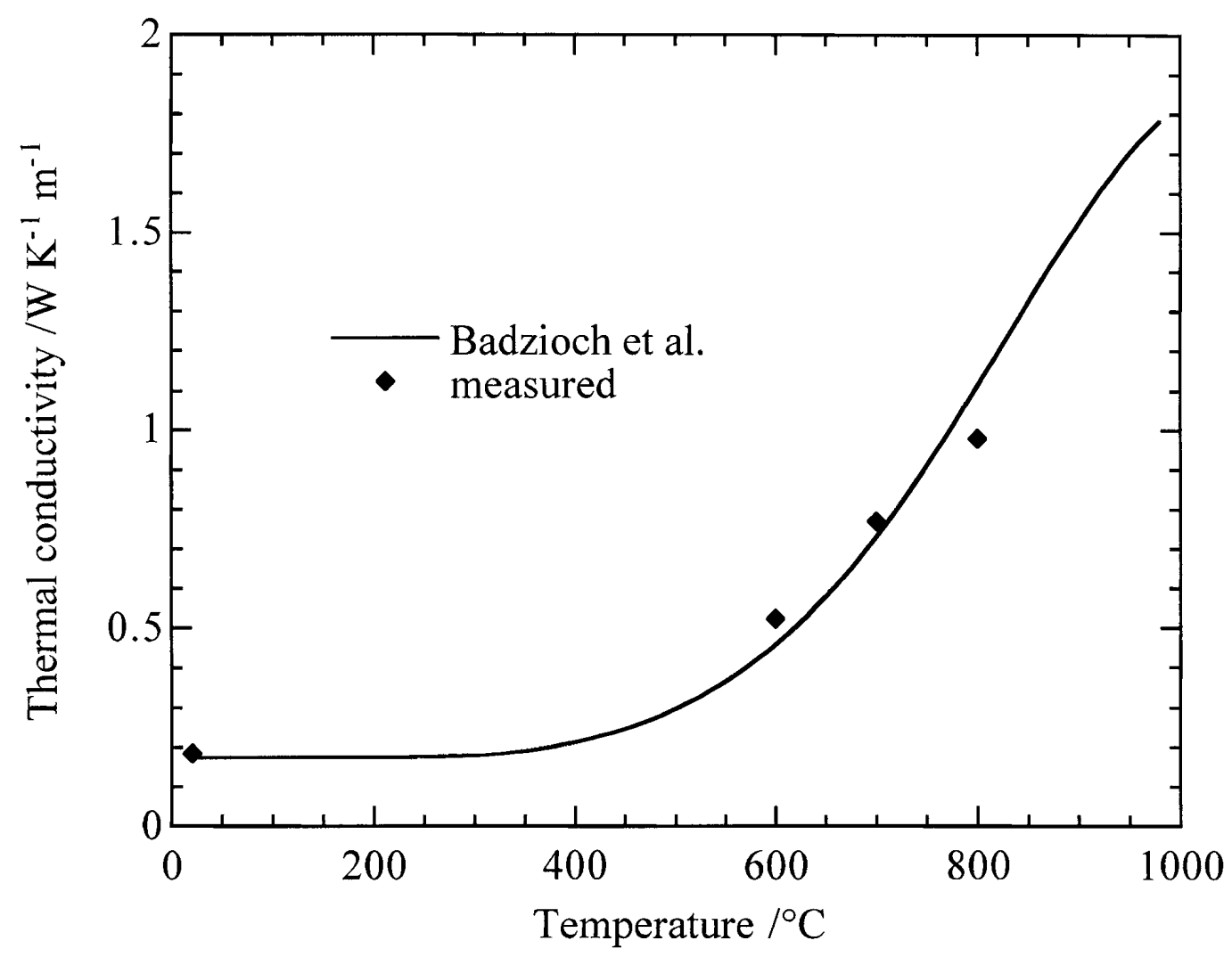

Fig. 5-Thermal conductivity of coal and semicoke as a function of temperature.

\section{Emissivity}

For a material such as coal, whose surface is heterogeneous, the thermal emissivity is difficult to measure. The values reported in the literature generally lie between 0.8 and 1 . Moreover, coal is usually considered to be a gray body, although the measurements of Solomon et al. ${ }^{[15]}$ on powdered coal indicate that, while the emissivity is 0.9 in certain regions of the emission spectrum, it can decrease markedly in other regions of the spectrum. The solid approaches a high emissivity gray body behavior as the pyrolysis advances and when the size of the grains increases. In the present case, the value $\varepsilon_{g r}=0.9$ was used, but at the same time was considered to be uncertain. It will be 
shown below that this parameter has in fact relatively little influence on the results of the grain model.

\section{E. Enthalpy of the pyrolysis reaction}

The enthalpy of the pyrolysis reaction has often been measured by calorimetry, ${ }^{[10,16-19]}$ or has been deduced from heat balances in coke ovens or Jenker crucible experiments. ${ }^{[20]}$ The enthalpies of reaction obtained range from -240 to +1400 $\mathrm{kJ} \mathrm{kg}^{-1}$. An endothermic peak followed by an exothermic peak is sometimes observed. ${ }^{[16]}$ However, other authors consider the reaction to be entirely exothermic ${ }^{[10,17]}$ or, on the contrary, strongly endothermic. ${ }^{[18,19]}$ Without taking the analysis of these results further, it should be noted that the type of coal studied is not the only cause of these marked differences. The majority of authors do not take into account the variation of the specific heat of the semi-coke during the reaction, nor the effects of weight loss. From this point of view, the results of Tromp et al. ${ }^{[18]}$ appear to be the most reliable, with an endothermic effect ranging from 175 to $385 \mathrm{~kJ} \mathrm{~kg}^{-1}$ depending on the type of coal studied.

We finally decided, somewhat arbitrarily, to take $\Delta H_{\text {pyro }}=300 \mathrm{~kJ} \mathrm{~kg}^{-1}$. However, as for $\varepsilon_{g r}$, this value is considered to be poorly defined, but it will be shown that it has little influence on the results of the grain model.

\section{THE MATHEMATICAL MODEL}

The grain model describes the pyrolysis reaction in a coal grain as a function of the external conditions. It describes the heat transfer in the transient regime towards and within the grain and takes into account the kinetics and heat of the different 
devolatilization reactions. The coupled equations for the local heat balance and the matter balances for the species considered are solved numerically. The thermophysical and kinetic parameters employed were determined by the measurements described above.

The model is one-dimensional in the transient regime. It is assumed that the spherical coal grain does not swell or crack. In contrast, the variation of the porosity is simulated via the change in density. The diffusion of the volatile species, which is not limiting at the heating rates of interest, is not modeled. Secondary cracking reactions are not treated as such, but are taken into account via the composition of the volatile species and the kinetics of devolatilization of the different constituents.

\section{A. Equations}

\section{Matter balances}

According to Eq. [1], the local balance for free water in the solid is :

$$
-\rho_{d c} \frac{\partial w_{f w}}{\partial t}=\rho_{d c} k_{d r} w_{f w}=v_{d r}
$$

Similarly, from Eq. [3], the local balance for the volatile species $j$ in the solid is :

$$
-\rho_{d c} \frac{\partial w_{j}}{\partial t}=\rho_{d c} k_{d e v, j} w_{j}=v_{j}
$$

The overall rate of pyrolysis is

$$
v_{\text {pyro }}=\sum_{j} v_{j}
$$

Eqs [8] and [9] are solved to calculate the weight fractions $w_{i}(r, t)$ from the following initial conditions: given initial moisture content $w_{f w_{0}}$ and volatile matter contents $w_{j_{0}}$ taken from Table 3. 
The density during pyrolysis is given by

$$
\rho=\rho_{d c}\left(1+w_{f w}+\sum_{j}\left(w_{j}-w_{j 0}\right)\right)
$$

The mass flux density $N_{g_{i}}$ for a gaseous species $i\left(i=f w, c w\right.$, tar, $\mathrm{CH}_{4}$, etc.), is determined from the balance

$$
\nabla \cdot \mathbf{N}_{g_{i}}=v_{i}
$$

considering that there is no accumulation of gas in the grain, corresponding to the pseudo-steady state assumption. This gives

$$
N_{g_{i}}(r)=\frac{1}{r^{2}} \int_{0}^{r} v_{i}(r) r^{2} d r
$$

\section{Heat balance}

The variation of enthalpy within the grain is the result of the consumption of heat by drying and pyrolysis, and transport by conduction and by convection of the gases produced :

$$
\rho c_{p} \frac{\partial T}{\partial t}+v_{d r} \Delta_{v} H_{\mathrm{H}_{2} \mathrm{O}}+v_{p y r o} \Delta_{r} H_{p y r o}-\frac{1}{r^{2}} \frac{\partial}{\partial r}\left(r^{2} \lambda \frac{\partial T}{\partial r}\right)+N_{g} c_{p_{g}} \frac{\partial T}{\partial r}=0
$$

In this equation, the solid and gas are assumed to be at the same temperature, $c_{p}$ and $\lambda$ are the functions of $T$ given in Figures 4 and $5, v_{d r}$ and $v_{p y r o}$ are the drying and pyrolysis rates given by Eqs [8] and [10], $\Delta_{v} H_{\mathrm{H}_{2} \mathrm{O}}$ is the enthalpy of vaporization of water, $\Delta_{r} H_{\text {pyro }}$ is the enthalpy of the pyrolysis reaction, and the last term represents the heating of the gases produced. The product $N_{g} c_{p_{g}}$ is

$$
N_{g} c_{p_{g}}=\sum_{i} N_{g_{i}} c_{p_{g_{i}}}
$$

where the $N_{g_{i}}$ values are given by Eq. [13]. 
Solution of Eq. [14] enables calculation of the temperature $T(r, t)$ if the initial and boundary conditions are known :

$$
\begin{gathered}
T(r, t=0)=T_{0} \\
\left.\frac{\partial T}{\partial r}\right|_{r=0}=0 \\
\left.\lambda \frac{\partial T}{\partial r}\right|_{r=R}=N_{q_{R}}
\end{gathered}
$$

where $N_{q_{R}}$ is the heat flux density received from the outside by convection and radiation. For a coal grain in the thermobalance

$$
N_{q_{R}}=h_{g-g r}\left(T_{g \infty}-T(R)\right)+E_{w-g r} \sigma\left(T_{w}^{4}-T(R)^{4}\right)
$$

where $h_{g-g r}$ is is the coefficient of convective heat transfer with the surrounding gas whose temperature is $T_{g_{\star}}$ and where $E_{w-g r}$ is an emissivity coefficient, depending on the emissivity of the grain and that of the wall at a temperature $T_{w}$ with which the grain exchanges heat by radiation. The coefficient $h_{g-g r}$ is calculated using the Ranz-Marshall correlation. ${ }^{[21]}$ For a coal grain in a rotary pyrolysis kiln, it is necessary to distinguish

- a grain at the surface of the charge bank, which receives heat from the gas and the wall by radiation and convection :

$$
N_{q_{R}}=h_{g-g r}\left(T_{g \infty}-T(R)\right)+E_{g-g r} \sigma\left(T_{g \infty}^{4}-T(R)^{4}\right)+E_{w-g r} \sigma\left(T_{w}^{4}-T(R)^{4}\right)
$$

- a grain in contact with the wall :

$$
N_{q_{R}}=h_{w-g r}\left(T_{w}-T(R)\right)
$$

- and a grain inside the charge, which does not exchange heat with its neighbors, assumed to be at the same temperature :

$$
N_{q_{R}}=0
$$


The way these different heat exchanges and the corresponding coefficients are calculated is described in Part 2. ${ }^{[22]}$

\section{B. Numerical solution}

The model is solved numerically by discretizing the balance equations using the finite volume method ${ }^{[23]}$ with an implicit formulation. The discretized heat balance gives a system of three-diagonal matrix equations which is solved using the TDMA algorithm. Since the heat and matter balance equations are coupled, with variable parameters, the complete system is solved at each time value by successive iterations until total convergence is obtained.

The grain is divided into 200 mesh cells of equal radial thickness. The time increment is constant and equal to $2 \mathrm{~ms}$. These values were taken sufficiently small so as not to influence the results, and sufficiently large to give reasonable computing times.

\section{Results}

For each time value, the model calculates the temperature $T$ and the composition $w_{i}\left(i=f w, c w, t a r, \mathrm{CH}_{4}\right.$, etc. $)$ at each point in the grain. It is also of interest to follow the degree of conversion $X_{i}$ of each species $i$ defined by

$$
X_{i}(t)=1-\frac{1}{V_{g r} w_{i_{0}}} \int_{V_{g r}} w_{i}(r, t) d V
$$

together with the overall progression of the pyrolysis $X_{\text {pyro }}$ defined by

$$
X_{\text {pyro }}(t)=1-\frac{1}{V_{g r} \sum_{j} w_{j_{0}}} \int_{V_{g r}} \sum_{j} w_{j}(r, t) d V
$$


Finally, to enable incorporation in the rotary kiln model, the molar fluxes $\Phi_{d e v, i, g r}^{*}$ are calculated for each gas evolved :

$$
\Phi_{d e v, i, g r}^{*}=\frac{N_{g_{i}}(R) S_{g r}}{M_{i}}=\frac{\rho_{d c} V_{g r} w_{i_{0}}}{M_{i}} \frac{d X_{i}}{d t}
$$

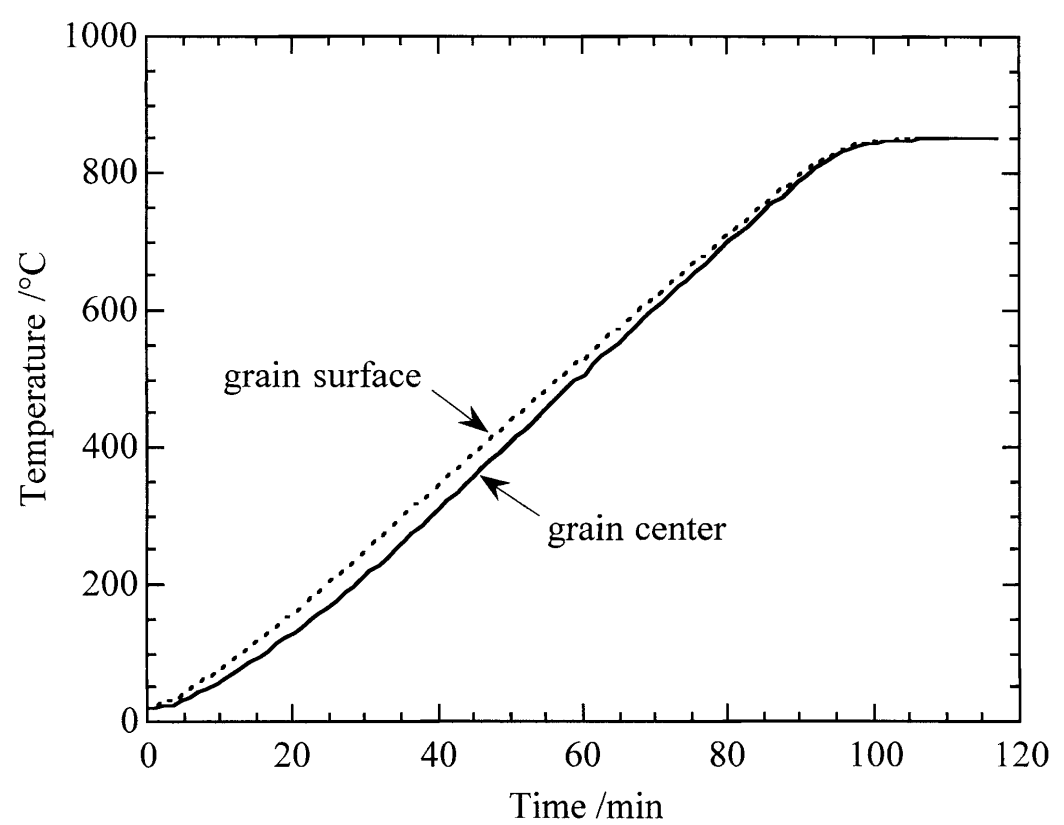

(a)

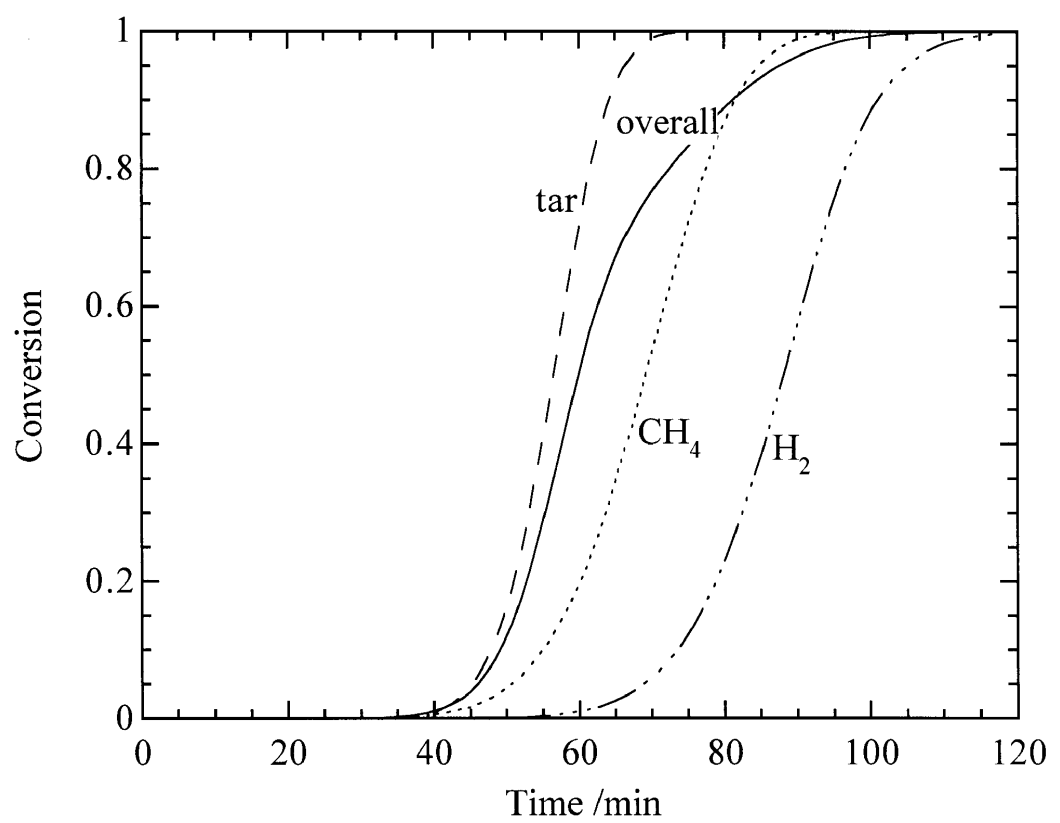

(b)

Fig. $6-(a)$ Calculated temperature and $(b)$ conversion during the pyrolysis of a coal grain at $8.7 \mathrm{~K} \mathrm{~min}^{-1}$. 
Figure 6 shows the variation of the temperature and the degree of conversion during pyrolysis of a $20 \mathrm{~mm}$ diameter coal grain heated at $8.7 \mathrm{~K} \mathrm{~min}^{-1}$ up to a holding temperature of $850^{\circ} \mathrm{C}$. Figure 6 a reveals the presence of a slight temperature gradient in the grain, the maximum temperature difference between the surface and the center being about $40^{\circ} \mathrm{C}$. Figure $6 \mathrm{~b}$ clearly illustrates the successive devolatilization of the different species, the evolution of hydrogen being completed only after attainment of the temperature plateau.

Among the different parameters in the model, some of them, in particular the enthalpy of the pyrolysis reaction and the emissivity of the coal grain, remain poorly defined. The sensitivity of the model to these two parameters was therefore tested. The results are given in Table 6 . The calculations concern a grain $20 \mathrm{~mm}$ in diameter, heated at either 8.7 or $27.7 \mathrm{~K} \mathrm{~min}^{-1}$. Over the range of values tested, the enthalpy of pyrolysis and the thermal emissivity of the grain have practically no influence, either on the maximum temperature difference between the center and surface $\Delta T_{\max }$, or on the time $t_{X_{p y r o}}=0.99$ taken to attain an overall conversion of 0.99. A more precise determination of $\Delta_{r} H_{p y r o}$ and $\varepsilon_{g r}$ does not therefore seem necessary. Nevertheless, it will be seen in Part 2 that $\Delta_{r} H_{\text {pyro }}$ influences the temperatures in the overall model of the rotary kiln.

\begin{tabular}{|c|c|c|c|c|}
\hline \multirow[b]{2}{*}{ Parameter } & \multicolumn{2}{|c|}{$\Delta T_{\max },{ }^{\circ} \mathrm{C}$} & \multicolumn{2}{|c|}{$t_{\text {Xyro }}=0.99, \mathrm{~s}$} \\
\hline & $8.7 \mathrm{~K} \mathrm{~min}^{-1}$ & $27.7 \mathrm{~K} \mathrm{~min}^{-1}$ & $8.7 \mathrm{~K} \mathrm{~min}^{-1}$ & $27.7 \mathrm{~K} \mathrm{~min}^{-1}$ \\
\hline$\Delta_{r} H_{\text {pyro }}=100 \mathrm{~kJ} \mathrm{~kg}^{-1}$ & 38.7 & 123.7 & 5780 & 2397 \\
\hline$\Delta_{r} H_{\text {руго }}=300 \mathrm{~kJ} \mathrm{~kg}^{-1}$ & 38.8 & 123.8 & 5796 & 2423 \\
\hline$\Delta_{r} H_{\text {pyro }}=1000 \mathrm{~kJ} \mathrm{~kg}^{-1}$ & 39.0 & 124.2 & 5858 & 2512 \\
\hline$\varepsilon_{\mathrm{gr}}=0.8$ & 38.8 & 123.8 & 5796 & 2423 \\
\hline$\varepsilon_{\mathrm{gr}}=0.9$ & 38.8 & 123.8 & 5790 & 2414 \\
\hline$\varepsilon_{\mathrm{gr}}=1$ & 38.8 & 123.7 & 5786 & 2408 \\
\hline
\end{tabular}

The calculated overall progress of the pyrolysis was compared to that given by the thermogravimetric measurements. It was verified that the model simulates the 
experiments in a quite satisfactory manner. This is illustrated by Figure 7 for a $10 \mathrm{~mm}$ diameter grain heated at $8.7 \mathrm{~K} \mathrm{~min}^{-1}$.

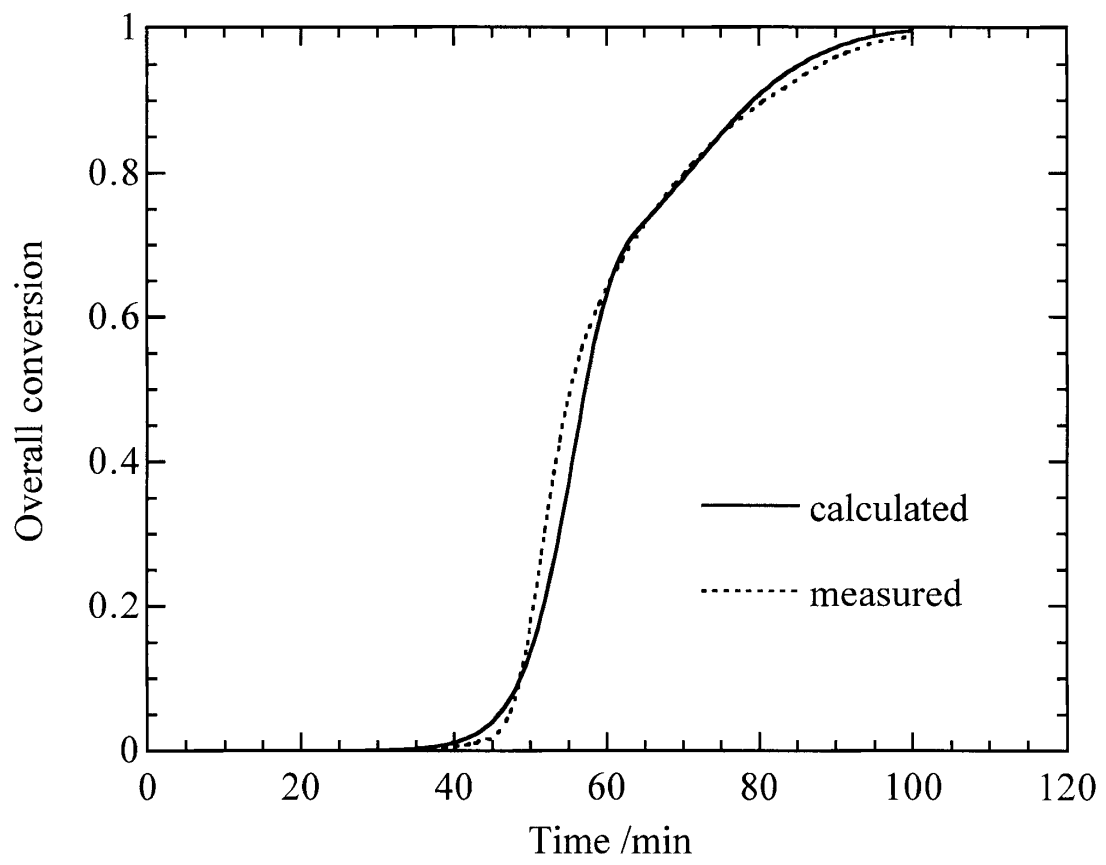

Fig. 7-Comparison of measured and calculated overall conversions of a 1 -cm-diameter coal grain pyrolyzed at $8.7 \mathrm{~K} \mathrm{~min}^{-1}$.

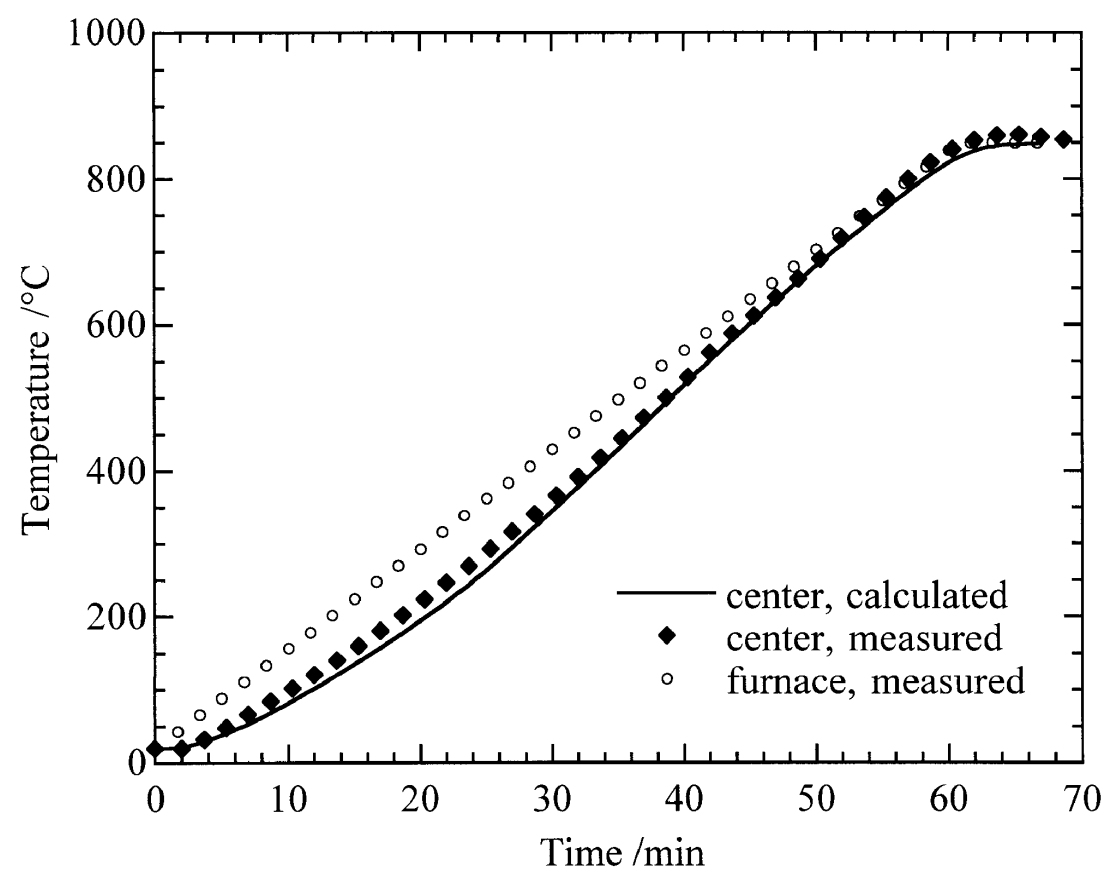

Fig. 8-Comparison of measured and calculated temperatures at the center of a 2-cm-diameter coal grain pyrolyzed at $13.8 \mathrm{~K} \mathrm{~min}^{-1}$. 
In the experimental conditions corresponding to this simulation, the temperature of the coal grain remains practically uniform $\left(\Delta T_{\max }=8^{\circ} \mathrm{C}\right)$. The above comparison is therefore essentially a validation of the kinetic laws employed. In order to check the validity of the thermal part of the calculation, the temperature at the center of a larger grain (20 mm diameter) was measured during faster pyrolysis (at $13.8 \mathrm{~K} \mathrm{~min}^{-1}$ ), by inserting a highly sensitive thermocouple, $0.5 \mathrm{~mm}$ in diameter. According to the model, the maximum temperature difference $\Delta T_{\max }$ is then $63^{\circ} \mathrm{C}$. Figure 8 shows that the temperature calculated at the center corresponds effectively to the measured value, and thus provides a validation of the thermal calculation performed in the grain model.

Finally, a problem was encountered when attempting to simulate the case of pyrolysis performed at much faster rates $\left(4 \mathrm{~K} \mathrm{~s}^{-1}\right)$, by introducing a cold coal grain directly into the hot thermobalance furnace. To correctly simulate such experiments with the grain model, it is necessary to assume that the heat flux received by radiation from the furnace wall is abnormally low. It is probable that at such high pyrolysis rates the evolution of volatile species is sufficiently intense to form a radiation absorbing screen around the grain. At slower pyrolysis rates, the volatile species produced are diluted in the external gas and this phenomenon does not occur. The present model, which is well adapted for heating rates between 8 and $30 \mathrm{~K} \mathrm{~min}^{-1}$, should therefore not be extrapolated to more rapid pyrolysis before having made a detailed study of the effect of radiation through the volatile species surrounding the grain.

\section{CONCLUSIONS}

Most of the thermophysical and kinetic data necessary for modeling the pyrolysis of Lorraine coal have been determined experimentally. In particular, the 
kinetic experiments performed have shown the necessity to separately describe the evolution of each different volatile species. Only the thermal emissivity of the coal and the enthalpy of the pyrolysis reaction remain uncertain. However, for the heating rates of practical interest, from 8 to $30 \mathrm{~K} \mathrm{~min}^{-1}$, these two parameters have only a very slight influence on the conversion.

The grain model presented here faithfully simulates the pyrolysis of a coal grain for given external conditions (temperature and composition of the gas, temperature of the radiating solid wall). Inside the rotary kiln, these conditions will vary along the kiln, depending on the position of the grain within the charge. When incorporated in the overall rotary kiln model presented in Part 2, the grain model enables precise and physically representative calculation of the conversion of the individual coal grains.

\section{ACKNOWLEDGEMENTS}

The authors are indebted to the Centre de Pyrolyse in Marienau for financial support and the collaboration of its engineers, in particular D. Isler and R. Bertau. Thanks are also due to the Centre National de la Recherche Scientifique which also assisted this work within the framework of the Groupement Scientifique "Pyrolyse du charbon".

\section{NOMENCLATURE}

$\begin{array}{ll}a & \text { thermal diffusivity } / \mathrm{m}^{2} \mathrm{~s}^{-1} \\ c_{p} & \text { specific heat } / \mathrm{J} \mathrm{kg}^{-1} \mathrm{~K}^{-1} \\ E & \text { activation energy } / \mathrm{J} \mathrm{mol}{ }^{-1} \text {, or emissivity coefficient } \\ h & \text { convective heat transfer coefficient } / \mathrm{W} \mathrm{m} \mathrm{m}^{-2} \mathrm{~K}^{-1}\end{array}$




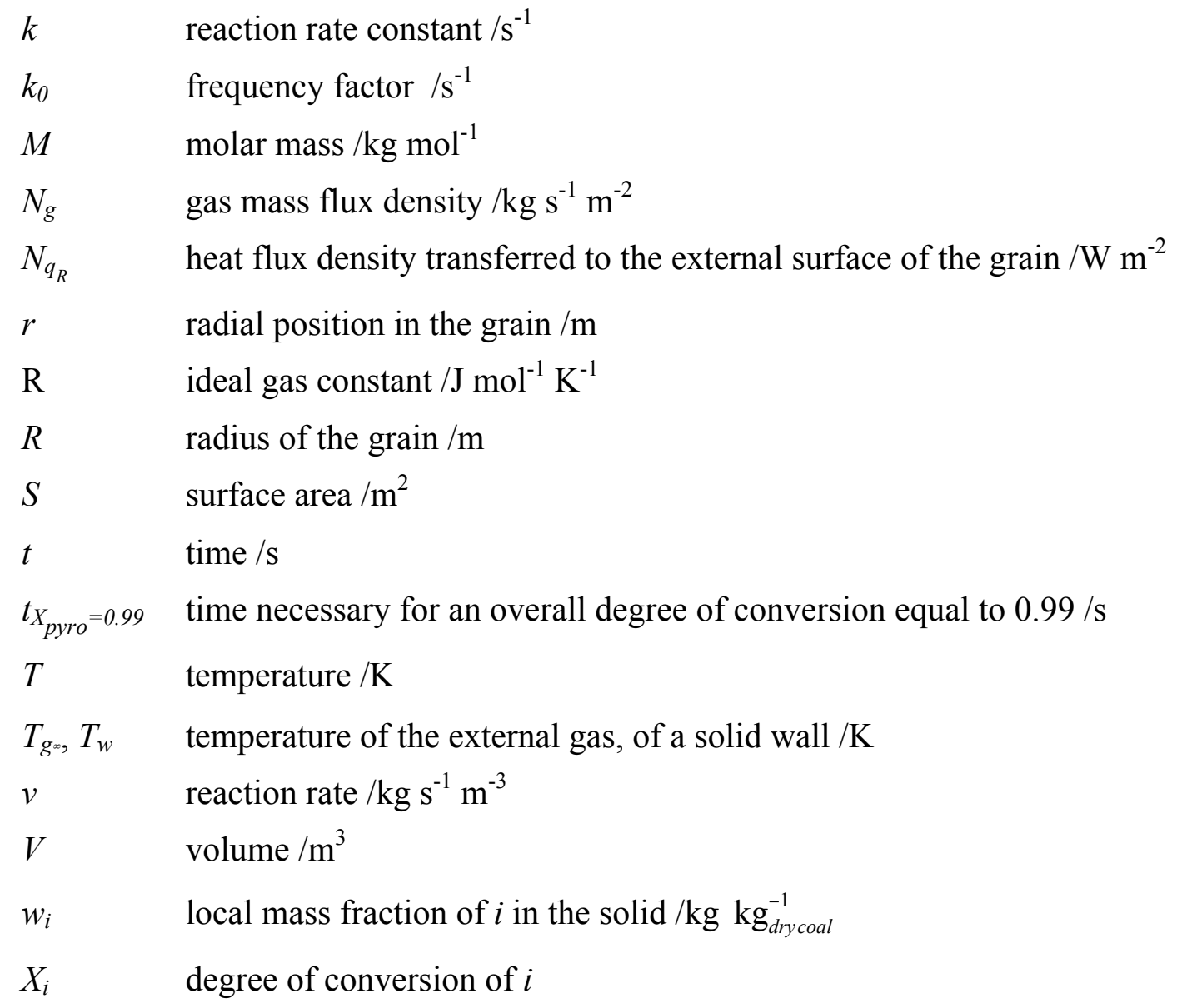

Greek symbols

$\Delta H \quad$ heat of reaction $\Delta_{r} H$, or of vaporization $\Delta_{v} H / \mathrm{J} \mathrm{kg}^{-1}$

$\Delta T_{\max } \quad$ maximum temperature difference between the surface and the center of the grain $/ \mathrm{K}$

$\varepsilon \quad$ emissivity

$\Phi_{d e v, i, g r}^{*} \quad$ molar flux of $i$ evolved from the grain $/ \mathrm{mol} \mathrm{s}^{-1}$

$\lambda \quad$ thermal conductivity $/ \mathrm{W} \mathrm{m}^{-1} \mathrm{~K}^{-1}$

$\rho \quad$ apparent density of the grain $/ \mathrm{kg} \mathrm{m}^{-3}$

$\underline{\text { Subscripts }}$

$\begin{array}{ll}0 & \text { initial } \\ c w & \text { constitutive water } \\ d e v & \text { devolatilization (i.e. evolution of volatile species) } \\ d r & \text { drying }\end{array}$




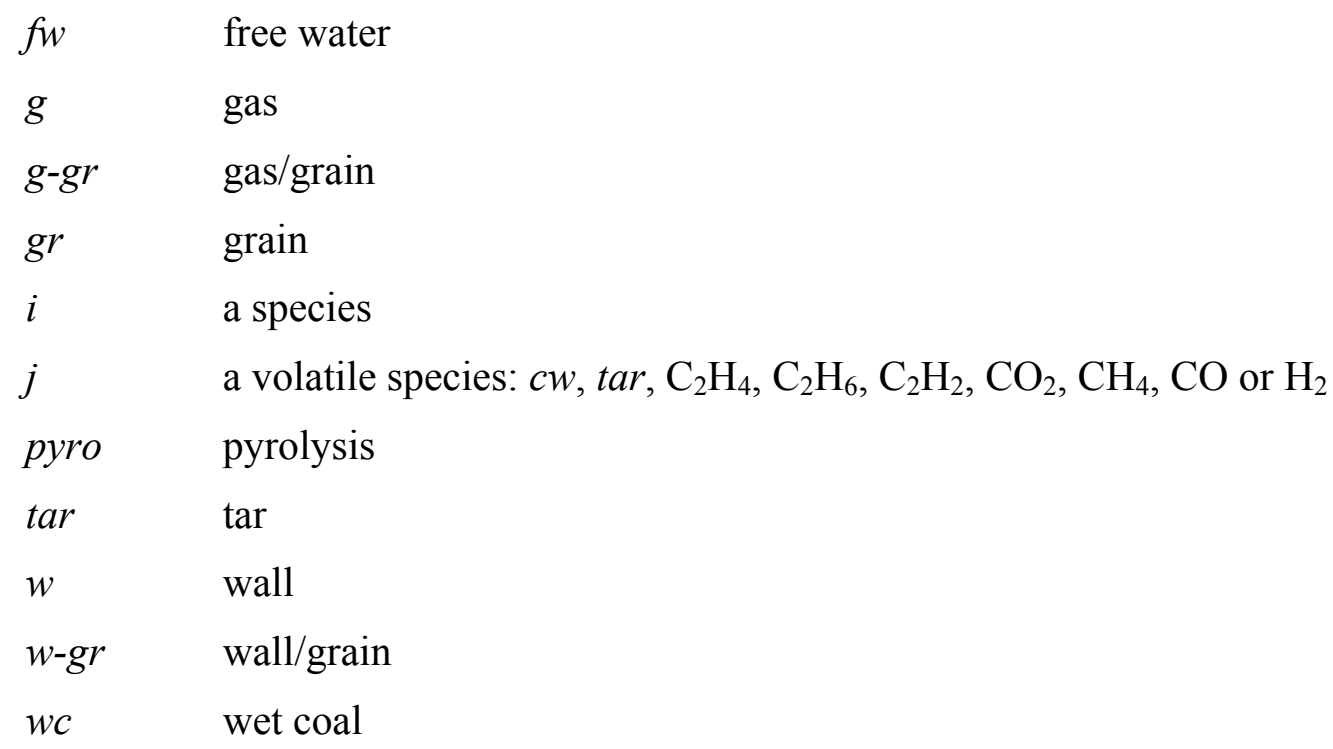

\section{REFERENCES}

1. F. Hanrot: Doctorate Thesis, Institut National Polytechnique de Lorraine, Nancy, 1992.

2. P.R. Solomon, M.A. Serio, and E.M. Suuberg: Prog. Energy Combust. Sci., 1992, vol. 18 , pp. 133-220.

3. G.R. Gavalas and K.A. Wilks: AIChE J., 1980, vol. 26, pp. 201-212.

4. P. Arendt and K.H. van Heek: Fuel, 1981, vol. 60, pp. 779-787.

5. R. Chirone and L. Massimilla: 22nd Symposium (Int.) on Combustion Proc., The Combustion Institute, Pittsburgh, 1988, pp. 267-277.

6. J.B. Howard and R.H. Essenhigh: Ind. Eng. Chem. Proc. Des. Dev., 1967, vol. 6, pp. 74-84.

7. D.B. Anthony and J.B. Howard: AIChE J., 1976, vol. 22, pp. 625-656.

8. E.M. Suuberg, W.A. Peters, and J.B. Howard: 17th Symposium (Int.) on Combustion Proc., The Combustion Institute, Pittsburgh, 1979, pp. 117-130. 
9. D. Merrick: Fuel, 1983, vol. 62, pp. 534-539.

10. D. Merrick: Fuel, 1983, vol. 62, pp. 540-553.

11. D. Merrick: in Coal Science and Chemistry, Edited by A. Volborth, 1987, pp. 307342.

12. F. Hanrot, D. Ablitzer, J.L. Houzelot, and M. Dirand: Fuel, 1994, vol. 73, pp. 305309.

13. S. Badzioch, D.R. Gregory, and M.A. Field: Fuel, 1964, vol. 43, pp. 267-280.

14. A. Degiovanni: Rev. Gén. Thermique, 1977, vol. 185, pp. 420-442.

15. P.R. Solomon, R.M. Carangelo, P.E. Best, J.R. Markham, and D.G. Hamblen: Fuel, 1987, vol. 66, pp. 897-908.

16. R.K. James and A.F. Mills: Letters Heat Mass Transfer, 1976, vol. 3, pp. 1-12.

17. R.S. Hefta, H.H. Schobert, and W.R. Kube: Fuel, 1986, vol. 65, pp. 1196-1202.

18. P.J.J. Tromp, F. Kapteijn, and J.A. Moulijn: Fuel Processing Technol., 1987, vol. 15, pp. $45-57$.

19. M. Hertzberg and I.A. Zlochower: Combust. Flame, 1991, vol. 84, pp. 15-37.

20. R. Loison, P. Foch, and A. Boyer: Le coke, qualité et production, CHERCHAR, Paris, 1990, pp. 553-566.

21. W.E. Ranz and W.R. Marshall: Chemical Engineering Progress, 1952, vol. 48, pp. 141-146 and 173-180.

22. F. Patisson, E. Lebas, F. Hanrot, D. Ablitzer, and J.-L. Houzelot: Metall. Mat. Trans., 1999, Part 2, submitted, ref : 99-21-B. 
23. S.V. Patankar: Numerical heat transfer and fluid flow, Hemisphere Publishing Corp., New York, 1980. 